\section{Commentary: Working downstream: Distal endovascular repair for retrograde type $A$ aortic dissection}

\author{
Madeline L. Fryer, MMSc, ${ }^{\mathrm{a}}$ and \\ Leora B. Balsam, $\mathrm{MD}^{\mathrm{b}}$
}

Open surgical repair has long been the standard of care for Stanford type A aortic pathologies, including intramural hematomas and both primary and retrograde dissections. Evidence is growing that suggests some of these patients may be adequately treated with less-invasive initial management. ${ }^{1-3}$ Nishi and colleagues ${ }^{4}$ present a case of thoracic endovascular repair for acute retrograde type A aortic dissection (TAAD) and demonstrate its feasibility in the setting of acute spinal cord ischemia.

The authors discuss multiple factors that guided their decision to perform an endovascular repair in this patient, including a primary entry tear at the T8 level, acute onset paraplegia, ascending aortic diameter $<50 \mathrm{~mm}$, thrombosed false lumen in the ascending aorta $<10 \mathrm{~mm}$, and lack of aortic regurgitation, pericardial effusion, or connective tissue disorder.

The report prompts further questions about which patients with acute retrograde TAAD are appropriate candidates for endovascular repair. Generally accepted criteria for emergent surgery include cardiac tamponade, aortic insufficiency, and underlying connective tissue disorder, but factors that identify patients as good endovascular candidates are less clear. Nonrandomized registry data of patients with acute retrograde TAAD analyzed by Nauta

\footnotetext{
From the ${ }^{\mathrm{a}}$ University of Massachusetts Medical School, Worcester, Mass; and ${ }^{\mathrm{b}}$ Division of Cardiac Surgery, UMass Memorial Medical Center, Worcester, Mass. Disclosures: The authors reported no conflicts of interest.

The Journal policy requires editors and reviewers to disclose conflicts of interest and to decline handling or reviewing manuscripts for which they may have a conflict of interest. The editors and reviewers of this article have no conflicts of interest.

Received for publication March 15, 2020; revisions received March 15, 2020; accepted for publication March 19, 2020; available ahead of print April 1, 2020.

Address for reprints: Leora B. Balsam, MD, Division of Cardiac Surgery, UMass Memorial Medical Center, University Campus, 55 Lake Ave N, Worcester, MA 01655 (E-mail: leora.balsam@umassmemorial.org).

JTCVS Techniques 2020;2:25-6

2666-2507

Copyright (C) 2020 The Authors. Published by Elsevier Inc. on behalf of The American Association for Thoracic Surgery. This is an open access article under the CC BY-NCND license (http://creativecommons.org/licenses/by-nc-nd/4.0/).

https://doi.org/10.1016/j.xjtc.2020.03.017
}

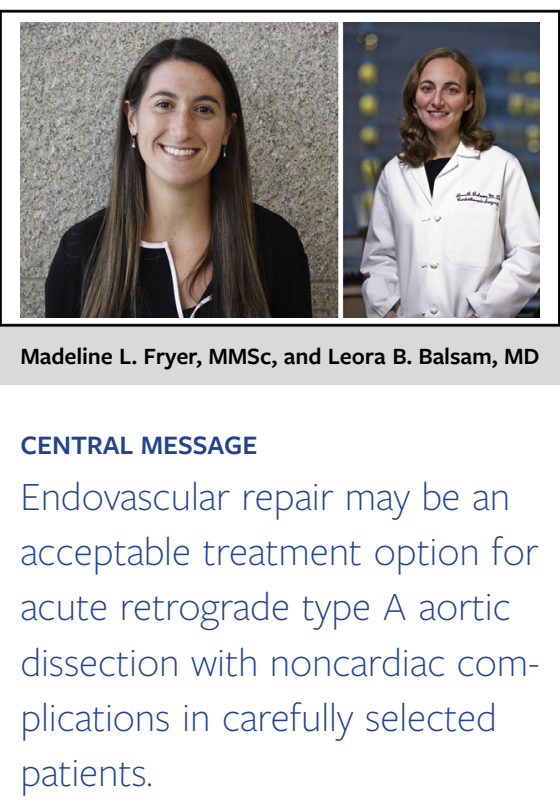

and colleagues ${ }^{2}$ showed that those with limb ischemia and smaller ascending aortic diameters are more likely to be selected for endovascular repair and have comparable outcomes compared with surgically managed counterparts. The single-center experience of Chen and colleagues ${ }^{3}$ also demonstrated that endovascular treatment of thrombosed retrograde TAAD or type A intramural hematoma is feasible with favorable early outcomes, although the sample size 6 six patients limits generalization of their outcomes. An additional dilemma is that most currently available data involve patients with spontaneous acute aortic injury, and the applicability of these results to patients with retrograde tears after previous endovascular aortic repair are unclear.

Although no objective criteria currently exist for identifying optimal endovascular repair candidates for acute retrograde TAAD, lessons can be learned about candidacy for conservative management from experience with type A intramural hematoma. Kitai and colleagues ${ }^{1}$ report that in 66 patients at their institution, patients treated with emergency surgery had similar outcomes as those undergoing initial medical management with close imaging follow-up. They recommend patients with complications, including cardiac tamponade, myocardial ischemia, and aortic regurgitation undergo immediate repair, but also suggest those with an ascending aortic diameter $\geq 50 \mathrm{~mm}$ be considered for emergency surgery to reduce the risk of mortality and longer hospital stay.

Nishi and colleagues ${ }^{4}$ report excellent early results in a single patient with acute retrograde TAAD treated with 
thoracic endovascular repair. Moving forward, it will be important to investigate objective criteria for endovascular repair and to follow long-term patient outcomes. This might lead to practice changes in a field where open surgery currently remains the gold standard.

\section{References}

1. Kitai T, Kaji S, Yamamuro A, Tani T, Tamita K, Kinoshita M, et al. Clinical outcomes of medical therapy and timely operation in initially diagnosed type a aortic intramural hematoma: a 20-year experience. Circulation. 2009;120: S292-8.

2. Nauta FJH, Kim JB, Patel HJ, Peterson MD, Eckstein HH, Khoynezhad A, et al. Early outcomes of acute retrograde dissection from the international registry of acute aortic dissection. Semin Thorac Cardiovasc Surg. 2017;29:150-9.

3. Chen YY, Yen HT, Wu CC, Huang DK. Thoracic endovascular aortic repair for type A intramural hematoma and retrograde thrombosed type A aortic dissection: a single-center experience. Ann Vasc Surg. 2020;65:224-31.

4. Nishi S, Arima D, Yoshimoto A, Suematsu Y. A case of thoracic endovascular aortic repair for acute retrograde type A aortic dissection with paraplegia. J Thorac Cardiovasc Surg Tech. 2020;2:20-2. 